\title{
Retracted: A new nano bismuth(III) salophen catalyst for green and efficient catalytic oxidation of sulfides into the corresponding sulfoxides
}

\author{
Mohammad Ghaem Tajgardoon, Marzieh Jafari, Ezzat Rafiee, Mostafa Feyzi and Mohammad Joshaghani*
}

\begin{abstract}
Retraction
This article was mistakenly published twice. For this reason this duplicate article has now been retracted. For citation purposes please cite the original: http://www.inljournal.com/?_action=articlelnfo\&article=14

Abstract

Bismuth(III) salophen as a new catalyst has been synthesized. Structural properties of this complex have been studied by Fourier transform infrared spectroscopy, X-ray diffraction, differential scanning calorimetry, and thermal gravimetric analyses. The average crystalline size of Bi-salophen particles was $86 \mathrm{~nm}$. Thermal analyses show that the complex is stable over $300^{\circ} \mathrm{C}$. Catalytic activity of this catalyst has been investigated in oxidation of sulfides. Different kinds of sulfides have been oxidized to the corresponding sulfoxides efficiently in the presence of sodium periodate as oxidant in glacial acetic acid as solvent at room temperature. These sulfides were selectively and completely converted into their corresponding sulfoxides in very short reaction times. Selectivity of this method was excellent, which is another advantage of this method.
\end{abstract}

Keywords: Bismuth(III) Schiff base, Oxidation, Sodium periodate, Sulfides, Salophen

\section{Background}

Schiff base complexes have been extensively used in a variety of applications including biological [1], clinical [2], analytical [3], and catalysis [4-11]. Recently, a number of reports have appeared describing the use of a Schiff base complex as a catalyst in the oxidation of sulfides [12-14]. On the other hand, many recent papers are describing the use of ecologically friendly bismuth compounds in organic transformations [15]. In addition, bismuth derivatives have been widely used in medicine [16]. They have attracted much attention because they are easy to handle, low in cost, and relatively insensitive to air and moisture [17]. In combining these two areas of interest, we are encouraged to use a Bi-salophen complex in the selective oxidation of sulfides into the corresponding sulfoxides (Scheme 1) which is an important method in organic synthesis because sulfoxides are useful synthetic intermediates for the construction of various chemically and biologically

\footnotetext{
* Correspondence: mjoshaghani@raziac.ir

Chemistry Department, Faculty of Science, Razi University, Kermanshah, 67149-67346, Iran
}

significant molecules [18]. Although there are several reagents available for this key transformation [19-27], finding more efficient and selective reagents is of a great challenge in organic transformations. Despite the need for careful control of the reaction temperature, reaction time and relative amounts of oxidants, it is difficult to avoid completely such over-oxidation [28-30]. As the sulfoxides are important for $\mathrm{C}-\mathrm{C}$ bond formation and functional group transformations, and in view of the recent trend on the catalytic processes towards the development of clean and green chemical processes, the search for newer methods for the catalytic selective oxidation of sulfides to the corresponding sulfoxides has continued.

\section{Methods}

\section{Materials and apparatus}

Bismuth(III) nitrate pentahydrate was purchased from Fluka (acquired by Sigma-Aldrich Corporation, St. Louis, MO, USA) and used as received. Glacial acetic acid was purchased from Merck AG (Darmstadt, Germany). All 

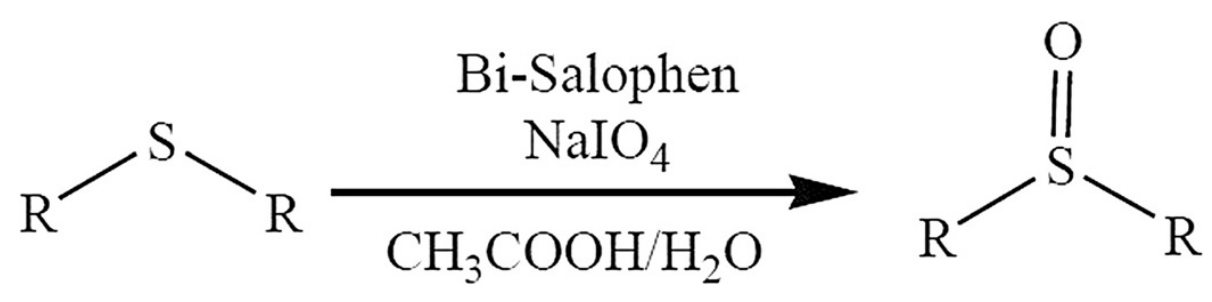

Scheme $1 \mathrm{Bi}$-salophen complex in the selective oxidation of sulfides.

other chemical compounds were commercially available from Merck or Fluka.

Fourier transform infrared spectroscopy (FT-IR) spectra were recorded using a Bomem MB 104 spectrometer (ABB Ltd., Zurich, Switzerland) using $\mathrm{KBr}$ pellets in the 400- to $4,000-\mathrm{cm}^{-1}$ range. Powder X-ray diffraction (XRD) measurements were performed using a BRUKER D8 Advance diffractometer (Ettlingen, Germany). Scans were taken with a $2 \theta$ step size of 0.02 and a counting time of $1.0 \mathrm{~s}$ using $\mathrm{Cu}-\mathrm{K \alpha}$ radiation source generated at $40 \mathrm{kV}$ and $30 \mathrm{~mA}$. Specimens for XRD were prepared by compaction into a glass-backed aluminum sample holder. Data were collected over a $2 \theta$ range from $4^{\circ}$ to $70^{\circ}$, and phases were identified by matching experimental patterns to entries in the Diffracplus version 6.0 indexing software (BRUKER AXS, Ettlingen, Germany). Thermal gravimetric analysis (TGA) and differential scanning calorimetry (DSC) were carried out using the simultaneous thermal analyzer apparatus of Rheometric Scientific Company (STA 1500+ Model, England) under a flow of dry air. The temperature was raised from room temperature to $600^{\circ} \mathrm{C}$ using a linear programmer at a heating rate of $5^{\circ} \mathrm{C} / \mathrm{min}$.

\section{General procedure for synthesis of Bi-salophen}

In a $100-\mathrm{mL}$ three-necked round-bottomed flask, $\mathrm{Bi}(\mathrm{NO} 3) 3.5 \mathrm{H} 2 \mathrm{O}(1.455 \mathrm{~g}, 3 \mathrm{mmol})$, ethanolic solution $(25 \mathrm{~mL})$ of o-phenylenediamine $(0.324 \mathrm{~g}, 3 \mathrm{mmol})$, and salicylaldehyde $(0.732 \mathrm{~g}, 6 \mathrm{mmol})$ were added. The resulting mixture was stirred and refluxed for $4 \mathrm{~h}$ on an oil bath. The progress of the reaction was monitored by thin layer chromatography (TLC) (eluent: n-hexane/ ethyl acetate, 1/8) until the initial phenylenediamine spot disappeared. The creamy precipitate was filtered off, washed with cold ethanol and toluene, and then was dried in the air. Melting point $(\mathrm{mp})=302^{\circ} \mathrm{C}$ (decomposed). Analytically calculated for $\mathrm{C} 20 \mathrm{H} 14 \mathrm{~N} 3 \mathrm{O} 5.5 \mathrm{H} 2 \mathrm{O}$ were $\mathrm{Bi}, 32.69 \%$; $\mathrm{C}, 37.57 \% ; \mathrm{H}, 3.15 \%$; and $\mathrm{N}, 6.57 \%$, and found values were $\mathrm{Bi}, 32.83 \%$; $\mathrm{C}, 37.72 \%$; $\mathrm{H}, 3.24 \%$; and $\mathrm{N}, 6.81$. FT-IR ( $\mathrm{KBr}$ pellets, $\mathrm{cm}^{-1}$ ) were $1,612,1,379$, 756,814 , and $3,452 \mathrm{~cm}^{-1}$.

\section{General procedure for oxidation of sulfide}

In a $25-\mathrm{mL}$ flask equipped with a magnetic stirring bar, a solution of sodium periodate $(0.0639 \mathrm{~g}, 0.3 \mathrm{mmol}$ in $\left.1 \mathrm{~mL} \mathrm{H}_{2} \mathrm{O}\right)$ was added to a mixture of sulfide $(0.1 \mathrm{mmol})$ and Bi-salophen $(0.00293 \mathrm{~g}, 0.005 \mathrm{mmol})$ in glacial acetic acid $(1 \mathrm{~mL})$. The progress of the reaction was monitored by TLC (eluent: n-hexane-ethyl acetate, 7/2). After the reaction was completed, the product was extracted with $\mathrm{CH}_{2} \mathrm{Cl}_{2}(20 \mathrm{~mL})$ and purified by a silica gel plate or a silica gel column. The identification of the product was confirmed by mp, FT-IR and ${ }^{1} \mathrm{H}-\mathrm{NMR}$ spectral data.

\section{Results and discussion \\ Catalyst characterization \\ FT-IR spectroscopy}

The FT-IR spectrum of the complex is in agreement with the proposed structure shown in Figure 1. A wide and strong band at $1,379 \mathrm{~cm}^{-1}$ strongly indicates that the nitrate ion is a counter ion. The characteristic bands corresponding to starting aldehyde and amine also disappeared. The other informative band is at $1,612 \mathrm{~cm}^{-1}$ due to the stretching frequency of $\mathrm{C}=\mathrm{N}$ which shows a shift toward a lower frequency due to coordination of nitrogen. The $\mathrm{O}-\mathrm{H}$ stretching frequency in the free ligand also disappeared which indicates that both oxygen lost their protons and coordinated with the bismuth ion.

\section{$X$-Ray diffraction}

In addition to common characterization tools, XRD was also used for the identification of crystalline phases and the evaluation of crystallite sizes using the Scherrer equation [20]. The average of crystalline size of Bi-salophen particles was $86 \mathrm{~nm}$ which was calculated from the most intense Bi-salophen line $\left(2 \theta=13^{\circ}\right)$ in the XRD spectrum (Figure 2). The spectrum indicates the presence of cubic and tetragonal forms of the catalyst.

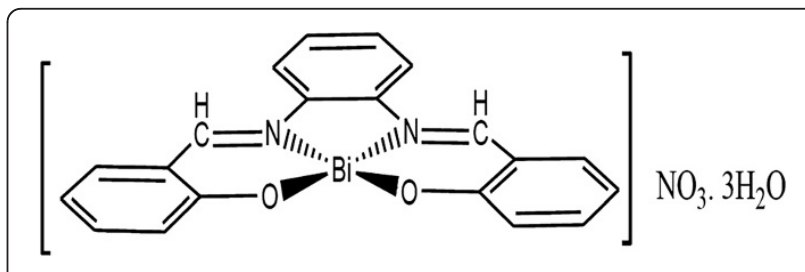

Figure 1 Structure of the bismuth(III) salophen catalyst. 


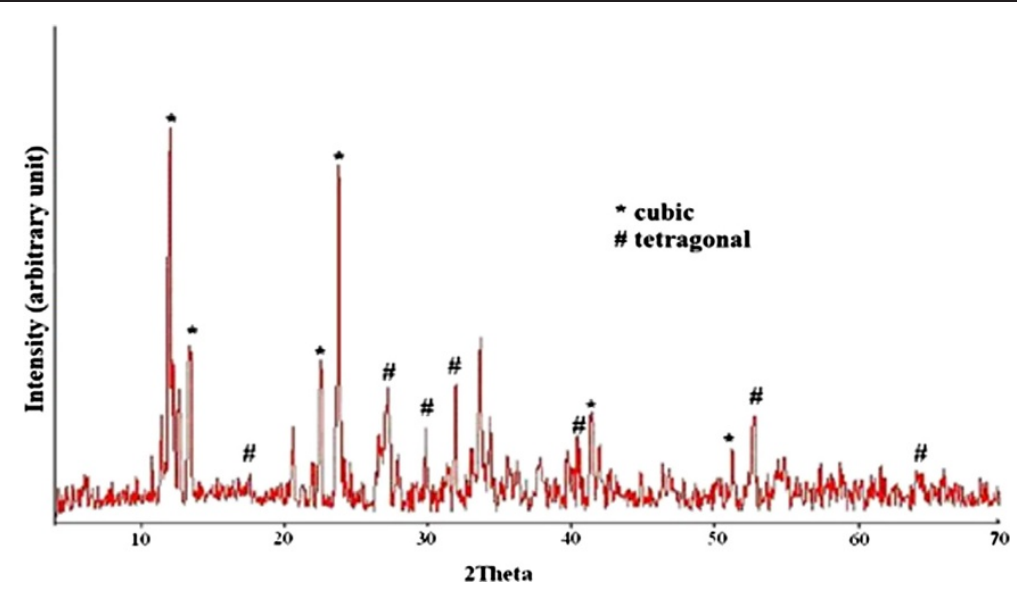

Figure $\mathbf{2}$ The XRD spectrum of the bismuth(III) salophen catalyst.

\section{Thermal gravimetric analysis and differential scanning calorimetry}

Thermal analyses were also performed to measure the stability of the catalyst as well as the amount of water of crystallization. The TGA/DSC curves for this catalyst are shown in Figure 3. The weight losses agreed fairly well with those expected for the decomposition of this complex. For this catalyst, the thermogravimetric curve seems to indicate a three-stage decomposition. The first endothermic stage is considered to be due to the removal of all three water of crystallization $\left(70^{\circ} \mathrm{C}\right.$ to $\left.90^{\circ} \mathrm{C}\right)$, and the second endothermic stage $\left(95^{\circ} \mathrm{C}\right.$ to $\left.295^{\circ} \mathrm{C}\right)$ is due to the decomposition of salophen and/or breaking of $\mathrm{Bi}-\mathrm{O}$ bonds, respectively. The latter temperature is equal to the decomposition point measured individually by the melting point apparatus. The third endothermic peak which was around $305^{\circ} \mathrm{C}$ to $370^{\circ} \mathrm{C}$ is due to the

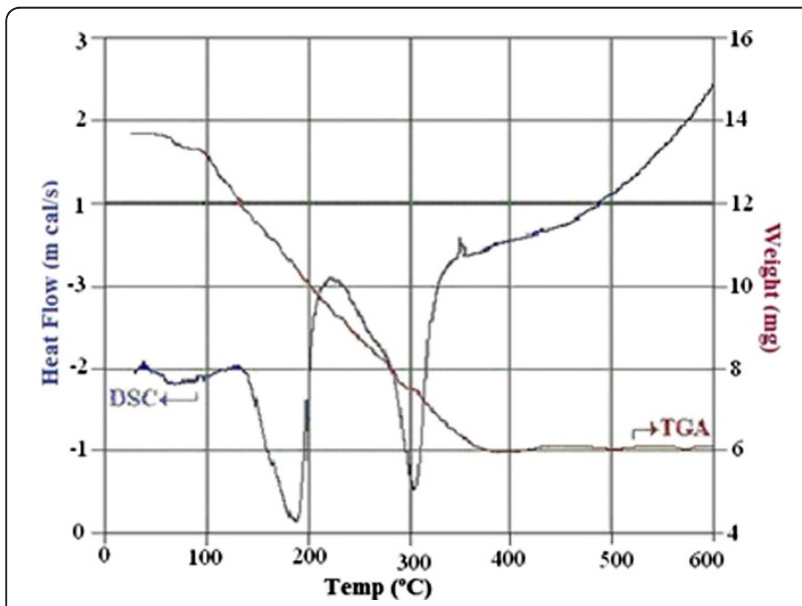

Figure 3 The TGA/DSC thermal analysis of the bismuth(III) salophen catalyst. decomposition of bismuth nitrate to the corresponding oxide. The TGA curve is involved with a total overall weight loss of ca. 66 wt.\%.

\section{Investigation of Bi-salophen catalytic activity}

In a preliminary approach to the periodate anion activation by metal Schiff base complexes, we decided to investigate the activity of $\mathrm{Bi}$-salophen in the catalytic oxidation of sulfides with $\mathrm{NaIO}_{4}$. The results are summarized in Table 1. A series of diaryl, dialkyl, dibenzyl, diallyl, aryl benzyl, alkyl aryl, cyclic, and heterocyclic sulfides underwent selective oxidation to afford the corresponding sulfoxides excellent yields at room temperature and at short reaction times. Alkyl aryl sulfides were selectively and completely converted into their corresponding sulfoxides in very short reaction times (Table 1, entries 1 to 3). In comparison, some transition metal Schiff base complexes were used for the catalytic oxidation of methyl phenyl sulfide but in very long reaction times (Table 2, entries 1 to 5). In addition, some of these systems suffer from other disadvantages such as production of sulfone as a side product due to over-oxidation [12]. Therefore, it is concluded that our system shows great advantages such as mild reaction conditions, shorter reaction times, selective and controlled oxidation, and a nontoxic catalyst employment.

Diphenyl sulfide was converted into diphenyl sulfoxide in an excellent yield (Table 1, entry 4). In comparison, the formation of sulfoxides from diaryl sulfides has been reported in very long reaction times and relatively hard reaction conditions, and sulfone has been produced as a side product due to over-oxidation [35-37].

Another useful feature of the presented protocol can be seen in the cases of benzyl aryl and dibenzyl sulfides (Table 1, entries 5 to 7), and diallyl sulfide (Table 1, 
Table 1 Oxidation of sulfides with $\mathrm{NaIO}_{4}$ catalyzed by Bi-salophen

Sulfoxides $\begin{gathered}\text { Time } \\ \text { (min) }\end{gathered}$
(\%)

7<smiles>c1ccc(CSCc2ccccc2)cc1</smiles><smiles>c1ccc2c(c1)sc1ccccc12</smiles><smiles>CCSCC</smiles><smiles>CCCSCCC</smiles>

Table 2 Comparative oxidation of methyl phenyl sulfide by some metal Schiff base systems

\begin{tabular}{lccccc}
\hline Entry & Metal & Oxidant & Time (h) & Yield (\%) & Reference \\
\hline 1 & $\mathrm{Mn}$ & $\mathrm{PhlO}$ & 5 & 70 & {$[12]$} \\
2 & $\mathrm{Ti}$ & $\mathrm{H}_{2} \mathrm{O}_{2}$ & 24 & 82 & {$[31]$} \\
3 & $\mathrm{Fe}$ & $\mathrm{PhlO}$ & 2 & 88 & {$[32]$} \\
4 & $\mathrm{~V}$ & $\mathrm{H}_{2} \mathrm{O}_{2}$ & 12 & 81 & {$[33]$} \\
5 & $\mathrm{Cu}$ & $\mathrm{H}_{2} \mathrm{O}_{2}$ & 4.5 & 90 & {$[34]$} \\
\hline
\end{tabular}

entry 12). No oxidation was observed at the benzylic C$\mathrm{H}$ bonds in the former cases. Also, neither over-oxidation to sulfone nor epoxidation of the double bond was observed in the latter case. Dibenzothiophene was selectively and completely converted into the corresponding sulfoxide in very short reaction times (Table 1, entry 8). In comparison, some transition metal Schiff base complexes were used for the catalytic oxidation of dibenzothiophene, but sulfone was produced as a side product due to over-oxidation [37].

\section{Conclusions}

In the course of our research, we found that bismuth(III) salophen is relatively nontoxic, easily synthesized on any scale at low cost, and fairly stable to water, unlike common Lewis acids (e.g., $\mathrm{AlCl}_{3}$ ) which readily decompose in aqueous media and selectively catalyze the oxidation of sulfides into their corresponding sulfoxides in very short reaction times and excellent yields.

\section{Competing interests}

The authors declare that they have no competing interest

\section{Acknowledgements}

The authors are grateful to the Kermanshah Oil Refining Company and the Razi University Research Council for the financial support of this work.

\section{Authors' contributions}

MGT participated in the experiments, MJ carried out the experiment, ER participated in the interpretation of organic transformations. MF participated in preparation and study of spectra. MJ conceived the study and participated in its design and coordination. All authors read and approved the final manuscript.

\section{Authors' information}

MGT, Ph.D. student of Computer Engineering. MJ, M. Sc. Student of Chemistry. ER, Associate professor of Chemistry. MF, Assistant Professor of Chemistry. MJ, Professor of Chemistry

Received: 30 October 2010 Accepted: 18 June 2012

Published: 18 June 2012

\section{References}

1. Singh, P, Goel, RL, Singh, BP: 8-acetyl-7-hydroxy-4-methyl coumarin as a gravimetric reagent for $\mathrm{Cu}^{2+}$ and $\mathrm{Fe}^{3+}$. J. Indian Chem. Soc. 52, 958 (1975)

2. Mohindru, A, Fisher, JM, Rabinovitz, M: Bathocuproine sulphonate: a tissue culture-compatible indicator of copper-mediated toxicity. Nature (London) 303, 64 (1983)

3. Patel, PR, Thaker, BT, Zele, S: Preparation and characterization of some lanthanide complexes involving a heterocyclic beta -diketone. Indian J. Chem., Sect A 38, 563 (1999) 
4. Lowenthal, RE, Abiko, A, Masamune, S: Asymmetric catalytic cyclopropanation of olefins: bis-oxazoline copper complexes. Tetrahedron Lett. 31, 6005 (1990)

5. Chang, CJ, Labinger, JA, Gray, HB: Aerobic Epoxidation of Olefins Catalyzed by Electronegative Vanadyl Salen Complexes. Inorg. Chem. 36, 5927 (1997)

6. Evans, DA, Woerpel, KA, Hinman, MM, Faul, MM: Bis(oxazolines) as chiral ligands in metal-catalyzed asymmetric reactions. Catalytic, asymmetric cyclopropanation of olefins. J. Am. Chem. Soc. 113, 726 (1991)

7. Fukauda, T, Katsuki, T: Highly enantioselective cyclopropanation of styrene derivatives using Co(III)-salen complex as a catalyst. Tetrahedron 53, 7201 (1997)

8. Uozumi, T, Kyota, H, Kishi, E, Kitayama, K, Hayashi, T: Homochiral 2, 2'-bis (oxazolyl)-1,1'-binaphthyls as ligands for copper(I)-catalyzed asymmetric cyclopropanation. Tetrahedron-Asymmetry 7, 1603 (1996)

9. Denmark, SE, Stavenger, RA, Faucher, AM, Edwards, JP: Cyclopropanation with diazomethane and bis(oxazoline)palladium(II) complexes. J. Org. Chem. 62, 3375 (1997)

10. Paluki, $\mathrm{M}$, Hanson, $\mathrm{P}$, Jacobsen, EN: Asymmetric oxidation of sulfides with $\mathrm{H}_{2} \mathrm{O}_{2}$ catalyzed by (salen)Mn(III) complexes. Tetrahedron Lett. 33, 7111 (1992)

11. Tong, J, Li, Z, Xia, C: Highly efficient catalysts of chitosan-Schiff base Co(II) and $\mathrm{Pd}(\mathrm{II})$ complexes for aerobic oxidation of cyclohexane in the absence of reductants and solvents. J. Mol. Catal. A. Chem 231, 197 (2005)

12. Cavazzini, M, Pozzi, G, Quici, S, Shepperson, I: Fluorous biphasic oxidation of sulfides catalysed by (salen)manganese(III) complexes. J. Mol. Catal. A: Chem. 204-205, 433 (2003)

13. Sippola, V, Krause, O, Vuorinen, T: Oxidation of lignin model compounds with cobalt-sulphosalen catalyst in the presence and absence of carbohydrate model compound. J. Wood Chem. Technol. 24, 323 (2004)

14. Ballistreri, FP, Barbuzzi, E, Tomaselli, GA, Toscano, RM, Mol, J: Oxidation of N, $\mathrm{N}$-benzylalkylamines to nitrones by $\mathrm{Mo}(\mathrm{VI})$ and $\mathrm{W}(\mathrm{VI})$ polyperoxo complexes. Catal. A: Chem. 114, 229 (1997)

15. Leitch, S., Addison-Jones, J., McCluskey, A.: Regioselective N- and C2electrophilic substitution of 3-substituted indoles. Tetrahedron Lett. 46, 2915 (2005)

16. McAuliffe, CA: Comprehensive Coordination Chemistry. Pergamon Press, London (1987)

17. Srivastava, N, Banik, BK: Bismuth nitrate-catalyzed versatile Michael reactions. J. Org. Chem. 68, 2109 (2003)

18. Leon Prasanth, K, Maheswaran, $\mathrm{H}$ : Selective oxidation of sulfides to sulfoxides in water using 30\% hydrogen peroxide catalyzed with a recoverable $\mathrm{VO}(\mathrm{acac})_{2}$ exchanged sulfonic acid resin catalyst. J. Mol. Catal. A: Chem 268, 45 (2007)

19. Brougham, P, Cooper, MS, Cummerson, DA, Heaney, H, Thompson, N: Oxidation reactions using magnesium monoperphthalate: A comparison with m-chloroperoxybenzoic acid. Synthesis, 1015 (1987)

20. Firouzabadi, $\mathrm{H}$, Mohammadpour-Baltrok, I: Zinc bismuthate $\mathrm{Zn}\left(\mathrm{BiO}_{3}\right)_{2}$ I. A useful oxidizing agent for the efficient oxidation of organic compounds. Bull. Chem. Soc. Jpn. 65, 1131 (1992)

21. Heaney, $\mathrm{H}$ : Oxidation reactions using magnesium monoperphthalate and urea hydrogen peroxide. Aldrichim. Acta. 26, 35 (1993)

22. Page, $P C B$, Heer, JP, Bethell, D, Collington, EW, Andrews, DM: A new system for catalytic asymmetric oxidation of sulfides using a hydrogen peroxide based reagent. Tetrahedron Lett. 35, 9629 (1994)

23. Khurana, JM, Panda, AK, Gogia, A: Rapid oxidation of sulfides and sulfoxides with sodium hypochlorite. Org. Prep. Proced. Int. 28, 234 (1996)

24. Hirano, M, Yakabe, S, Clark, JH, Morimoto, T: Synthesis of sulfoxides by the oxidation of sulfides with sodium chlorite catalysed by manganese(III) acetylacetonate in acetone in the presence of alumina. J. Chem. Soc. Perkin. Trans, 2693 (1996)

25. Hirano, M, Komiya, K, Yakabe, S, Clark, JH, Morimoto, T: Org. Prep. Proced Int. 28, 705 (1996)

26. Yamazaki, S: Selective Ssnthesis of sulfoxides and sulfones by methyltrioxorhenium-catalyzed oxidation of sulfides with hydrogen peroxide. Bull. Chem. Soc. Jpn. 28, 2955 (1996)

27. Chen, F, Wan, J, Guan, C, Yang, J, Zhang, H: Tetrabutylammonium peroxydisulfate in organic synthesis; III. An efficient procedure for the selective oxidation of sulfides to sulfoxides by tetrabutylammonium peroxydisulfate. Synth. Commun. 26, 253 (1996)

28. Donohoe, TJ: Oxidation and Reduction in Organic Synthesis. Oxford University Press, New York (2000)
29. Ravikumar, KS, Barbier, F, Begue, JP, Bonnet-Delpon, D: Selective oxidation of sulfides: selective preparation of 1-trifluoromethyl vinyl sulfoxides. J. Fluorine. Chem. 95, 123 (1999)

30. $\mathrm{Xu}, \mathrm{WL}, \mathrm{Li}, \mathrm{YZ}$, Zhang, QS, Zhu, HS: A selective, convenient, and efficient conversion of sulfides to sulfoxides. Synthesis, 227 (2004)

31. Saito, B, Katsuki, T: Ti(salen)-catalyzed enantioselective sulfoxidation using hydrogen peroxide as a terminal oxidant. Tetrahedron Lett. 42, 3873 (2001)

32. Sivasubramanian, VK, Ganesan, M, Rajagopal, S, Ramaraj, R: Iron(III) - salen complexes as enzyme models: Mechanistic study of oxo(salen)iron complexes oxygenation of organic sulfides. J. Org. Chem. 67, 1506 (2002)

33. Sun, J, Zhu, C, Dai, Z, Yang, M, Pan, Y, Hu, H: Efficient asymmetric oxidation of sulfides and kinetic resolution of sulfoxides catalyzed by a vanadium - salan system. J. Org. Chem. 69, 8500 (2004)

34. Velusamy, S, Kumar, AV, Saini, R, Punniyanurthy, T: Copper catalyzed oxidation of sulfides to sulfoxides with aqueous hydrogen peroxide. Tetrahedron Lett. 46, 3819 (2005)

35. Hosseinpoor, F, Golchoubian, H: Mn(III)-catalyzed oxidation of sulfides to sulfoxides with hydrogen peroxide. Tetrahedron Lett. 47, 5195 (2006)

36. Karimi, B, Ghoreishi-Nezhad, M, Clark, H: Selective oxidation of sulfides to sulfoxides using $30 \%$ hydrogen peroxide catalyzed with a recoverable silicabased tungstate interphase catalyst. Org. Lett. 7, 625 (2005)

37. Mirkhani, V, Tangestaninejad, S, Moghadam, M, Mohammadpoor-Baltork, I, Kargar, H: Efficient oxidation of sulfides with sodium periodate catalyzed by manganese(III) Schiff base complexes. J. Mol. Catal. A: Chem. 242, 251 (2005)

doi:10.1186/2228-5326-2-8

Cite this article as: Tajgardoon et al:: Retracted: A new nano bismuth(III) salophen catalyst for green and efficient catalytic oxidation of sulfides into the corresponding sulfoxides. International Nano Letters 2012 2:8.

\section{Submit your manuscript to a SpringerOpen ${ }^{\odot}$ journal and benefit from:}

- Convenient online submission

Rigorous peer review

- Immediate publication on acceptance

- Open access: articles freely available online

- High visibility within the field

- Retaining the copyright to your article

Submit your next manuscript at $>$ springeropen.com 